\title{
Technological innovation, social learning and natural hazard mitigation: evidence on earthquake fatalities
}

\author{
QING MIAO \\ Department of Public Policy, Rochester Institute of Technology, Eastman \\ Hall 1-3242, 92 Lomb Memorial Drive, Rochester, NY 14623-5604, USA. \\ Tel: +1 585-475-7136. Email: Qing.Miao@rit.edu
}

Submitted 26 October 2015; revised 19 November 2016; accepted 24 November 2016; first published online 20 February 2017

\begin{abstract}
How do people learn from disasters? Do they constantly develop and accumulate new knowledge that enables them to address recurrent disaster risks? This paper investigates whether social learning and, in particular, the development of earthquakemitigating technologies reduces earthquake-induced fatalities. Combining patent data with a global cross-section of 894 earthquakes that occurred between 1980 and 2010, we find that countries with more disaster-mitigating innovations and more earthquake exposure in the past suffer fewer fatalities. This study is the first to empirically examine the role of technological change and social learning in disaster mitigation. It sheds light on knowledge as a key element of adaptive capacity, and suggests the importance of incorporating technology development into a long-term hazard mitigation and adaptation policy. The paper also contributes to the empirical disaster literature as the first to address the problem of missing data on disaster losses.
\end{abstract}

\section{Introduction}

A natural disaster occurs when hazard meets vulnerability. Although most natural disasters are triggered by exogenous shocks, their actual impacts on societies depend on the local capacity to prepare for and cope with disaster risks (Cutter et al., 2003). Why some communities suffer greater losses and what affects their ability to tackle natural hazards are important questions in the economics of natural disasters and also highly relevant to policy makers. To date, the empirical literature has focused mainly on two factors, income and institutions, and has provided consistent evidence that countries with higher income and better institutions suffer fewer fatalities from natural disasters (e.g., Kahn, 2005; Toya and Skidmore, 2007). The conceptual argument is that these countries generally have better infrastructure

This work was supported by DOE grant \#DE-SC0005171. The author thanks Professors David Popp, Pete Wilcoxen, Doug Wolf, Sarah Hamersma and Rebecca Schewe for their valuable comments. 
and mitigating technologies, and tend to adopt more effective regulations and emergency management practices, as well as other precautionary measures, which lead to better protection against disasters.

While the existing literature mostly estimates the aggregated effects of socio-economic conditions on disaster losses, research on more disaggregated mechanisms of disaster mitigation is lacking. In this paper, we go beyond the traditional focus on income and institutions, and consider learning and innovation as an important channel through which societies adapt to natural disasters. More specifically, we examine earthquake losses and link them with two forms of knowledge: (1) formal/technical knowledge (innovation), which is measured by the accumulation of patents in earthquake-proof building technologies in a country; and (2) informal knowledge, which is measured by a nation's prior earthquake experiences, because conventional wisdom holds that past disaster shocks incentivize people to undertake or improve protective measures that can lower damages caused by future disasters. Our central prediction is that countries with more quake-proof building innovations and greater earthquake exposure in the past are better adapted to earthquakes; therefore, they suffer fewer losses from current shocks.

Our research contributes to the disaster economics literature by exploring other possible mechanisms that can reduce disaster fatalities and elucidating the role of knowledge in societal adaptation to natural disasters. One unique contribution of this research is using patent data to empirically estimate the extent to which technical innovations reduce disaster impacts. Although the importance of science and technology development has been widely recognized in the disaster policy world (e.g., United Nations International Strategy for Disaster Reduction, 2009), there is little empirical research delving into this issue. The development of risk-mitigating technologies deserves special attention for two reasons. First, technical change may potentially serve as a separate mechanism for reducing disaster risk, and investigating the disaggregated effects beyond income and institutions allows us better to understand the determinant of adaptive capacity and inform policy decisions. Secondly, new knowledge derived from innovation serves as a public good because it can be adopted by non-inventors and yields substantial social benefits at home and abroad. In the global context, although a vast majority of the R\&D activities are performed by industrialized countries (National Science Board, 2010), the developing world can potentially exploit the risk-mitigating knowledge produced by their developed counterparts. Hence, in this research, we also investigate the possibility of international knowledge spillovers by testing whether foreign technical innovations can reduce a country's own earthquake losses.

In addition to formal technical knowledge, we account for social learning in disaster mitigation by including a country's experience with previous earthquakes as a proxy for its informal and experiential knowledge for coping with earthquakes. Controlling for the earthquake experiences is also important because the past events may induce the development of more risk-mitigating technologies, as suggested in Miao and Popp (2014). Several recent studies have examined similar questions by testing whether 
countries exposed to greater disaster risks on average suffer fewer losses (e.g., Keefer et al., 2011; Neumayer et al., 2014; Escaleras and Register, 2016). Most of them treat disaster exposure as a country-specific, time-constant characteristic by summing up the frequency or magnitude of certain types of natural hazards over an extended period. Our research differs from these studies by considering the learning dynamics and creating a weighted experience stock, assuming that people are more responsive to more recent shocks.

This paper also contributes to the empirical disaster literature by addressing the issue of missing data on disaster losses, which is a serious problem for widely used disaster databases such as the Emergency Events Database (EM-DAT). The earthquake data used in this paper are drawn from the National Geophysical Data Center's (NGDC) Significant Earthquake Database because it provides more details on earthquake physics than the EM-DAT does. Similarly to the EM-DAT, a considerable proportion of the events in the NGDC database have missing values on earthquake-related deaths and damages. Therefore, we employ multiple estimation strategies to address the missing data issue and obtain consistent results across different models.

Using a global cross-section of 894 earthquake events that occurred in 79 countries between 1980 and 2010, our research shows that both technical knowledge stocks and past cumulative earthquake experiences play an important role in reducing a country's fatalities from earthquakes, after controlling for the physical quake magnitude and other relevant national attributes. The effect of prior experiences on risk reduction is more pronounced in developed countries, while this influence largely operates through the mechanism of technological development. We do not find convincing evidence on the effects of foreign technical knowledge stocks on reducing earthquake losses. Overall, our findings highlight the importance of incorporating technological innovation as part of a long-term hazard mitigation and adaptation policy, and also suggest the need for more policy efforts at the international level to facilitate the diffusion and transfer of risk-mitigating technologies across countries.

The remainder of this paper is organized as follows. Section 2 discusses the relevant literature, and our conceptual framework and empirical model are presented in section 3. This is followed by the data and estimation strategies described in section 4 . The main estimation results are presented in section 5 and the paper concludes in section 6.

\section{Relevant literature}

This paper draws on a growing empirical literature on the determinants of disaster impacts and climate adaptation (for a review of the recent literature, see Kousky, 2014). As discussed earlier, this literature has traditionally focused on income and institutions (e.g., democracy, public sector corruption, inequality, governance) as the key determinants of natural disaster fatalities and damages (Anbarci et al., 2005; Kahn, 2005; Rashky, 2008; Keefer et al., 2011; Ferreira et al., 2013; Escaleras and Register, 2016). 
Very few studies have looked into the link between natural disasters and technological change. One exception is Barreca et al. (2016), who examine how the adoption of residential air conditioning reduces mortalities from the extremely hot weather in the United States. This paper further extends this line of research by using a cross-country sample and focusing more specifically on technological innovation. Specifically, this paper draws on Miao and Popp (2014), who examine the impact of three types of natural disasters - including earthquakes, floods and droughts - on the innovation of their relevant mitigating technologies and find consistent evidence that recent disaster shocks spur technical innovations. While their paper suggests the private sector adapts to natural hazards by innovating, this paper goes a further step by asking whether these risk-mitigating innovations lead to significant reductions in disaster losses.

Although the hazard literature is largely silent on the effect of knowledge, several studies have examined the 'learning-by-doing' effect by estimating the extent to which a country's historic earthquake exposure affects its losses, hypothesizing that countries at higher levels of risk are better adapted to the relevant hazards. For example, Anbarci et al. (2005) measure earthquake exposure by calculating the number of $6+$ Richter scale quakes a country has experienced over a long period, with only the latter providing modest evidence on an inverse relationship between exposure and fatalities. Keefer et al. (2011) take a slightly different approach by using the sum of physical strength (explosive equivalent) of large earthquakes between 1960 and 2008 as a proxy for a country's earthquake propensity. They show that not only do countries more prone to earthquakes suffer fewer fatalities, but also that this reduction effect is larger in developed and less corrupt nations. Neumayer et al. (2014) test a similar hypothesis in a multi-hazard study using a global sample of earthquakes, tropical cyclones and floods. They utilize a quantile regression and find that a country's disaster propensity has more pronounced effects in reducing economic losses of larger events (in the upper quantile of the damage function).

Similar evidence on adaptation motivated by hazard exposure was presented in studies of other types of natural hazards (e.g., Sadowski and Sutter, 2008; Schumacher and Strobl, 2011; Hsiang and Narita, 2012; Bakkensen and Mendelsohn, 2016). However, one problem arising from most of these studies is their measurement of hazard exposure using a summed disaster frequency or magnitude variable over the entire study period, which in fact is only realized at the end of the period. Even though the likelihood that a country experiences certain natural hazards can be constant from a statistical point of view, people do not always perceive the risk at the same level over time. Using a time-invariant risk measure to identify adaptation not only raises measurement concerns, but also ignores the learning dynamics by simply assuming the tendency to adapt to disasters is always constant within a country.

In fact, disaster-induced learning has been examined in a number of recent studies which posit that the occurrence of disasters provides new information to update people's risk perception and trigger changes in their risk-taking behaviors. Specifically, research has shown that experiencing major flooding events increases purchases of flood insurance and 
decreases the values of properties in flood-affected areas (e.g., Atreya et al., 2013; Gallagher, 2014; Kousky, 2016). However, these studies also find that the learning effects only persist for a relatively short time period and then decay to the pre-disaster levels, suggesting post-disaster learning may follow a Bayesian updating process that incorporates discounting of earlier disaster experiences. In other words, people can accumulate knowledge over time from their disaster experiences, but they may forget the earlier events or perceive them to be less relevant for judging their current risk, which implies a depreciation of knowledge. For example, Sadowski and Sutter (2008) find that a prior land-falling hurricane can significantly reduce current damages but the effect largely disappears beyond the 10-year time window. Motivated by this literature, our paper uses a discounting model in calculating a country's cumulative earthquake exposure to measure its informal knowledge stocks.

Finally, we draw on the literature regarding knowledge spillovers to motivate our investigation of the potential effect of technical innovations on global disaster risk reduction. The notion is that new technologies are public goods, meaning the knowledge embodied in technical innovations can be accessed and adopted by non-inventors, thereby generating substantial social benefits (Stephan, 1996). Most empirical studies in this field focus on knowledge spillovers in the global context and mainly examine two issues: the effect of technology spillovers on economic development and productivity growth, as well as the mechanism of knowledge spillovers (for a review of this literature, see Keller, 2001). Our research adds to this literature by using disaster damages as a new outcome measure and examining the effects of foreign knowledge stocks on earthquake fatalities across countries.

\section{Modeling}

\subsection{Conceptual framework}

To understand how societies acquire knowledge from their past disaster experiences to mitigate future hazard risks, we begin with a typical disaster damage function in which losses from a natural disaster $(L)$ are a function of the physical intensity of the disaster $(M)$, the local population exposure to the hazard $(P O P)$ and their capacity to cope with the shock $(C)$.

$$
L=f(M, P O P, C)
$$

We conceptualize knowledge as an important component of adaptive capacity, which includes both formal technical knowledge (TK), as measured by patented innovations, and informal knowledge (IK) of coping with disasters. It is important to note that, although formal knowledge is often developed by experts (e.g., seismic engineers in the case of earthquakes), informal knowledge could be experiential, indigenous and laymen's understanding of disaster probabilities and severity as well as related coping strategies. We model a country's adaptive capacity $(C)$ as a function of hazard knowledge $(T K, I K)$, income $(Y)$, institutions $(I)$ and 
other socio-economic characteristics $(X)$ that may influence its ability to prepare for and respond to natural disasters.

$$
C=f(T K, I K, Y, I, X)
$$

Two things are important to note here. First, $I K$ is not directly observed and thus is measured by prior disaster experiences (EXP) because we expect people to learn from their previous disaster experiences and accumulate knowledge of better protection against future disasters. Another reason for considering how disaster experiences affect knowledge is that the efficacy of disaster-mitigating measures (e.g., quake-proof buildings) is unknown until a disaster occurs (Neumayer et al., 2014). Secondly, the capacity to develop new knowledge also correlates with a country's income level, institutions and other socio-economic characteristics that are determinants of adaptive capacity. Combining equations (1) and (2) and replacing $(I K)$ with disaster $(E X P)$, we obtain the reduced-form relationship as follows:

$$
L=f(M, P O P, T K, E X P, Y, I, X)
$$

based on which we posit that a country that has accumulated more hazardmitigating knowledge and more hazard experiences suffers fewer losses from the current disaster shocks. ${ }^{1}$ Because the knowledge-generating process varies across countries depending on their socio-economic status, it is particularly important to account for other national attributes that may simultaneously affect learning and disaster losses in the model to avoid omitted variable bias.

\subsection{Empirical model}

Based on the conceptual model, we estimate the following equation:

$$
\begin{aligned}
D_{e c t}= & f\left(M_{e c t}, P O P_{e c t}, T K_{c, t-1}, E X P_{c, t-1}, Y_{c, t-1},\right. \\
& \left.I_{c, t-1}, X_{c, t-1}, c_{\text {ontinent }}, \theta_{t}, \varepsilon_{e c t}\right),
\end{aligned}
$$

where $D_{e c t}$ is fatalities from earthquake $i$ in country $c$ and year $t, M$ denotes variables measuring the physical magnitude of the earthquake (Richter scale and focal depth), POP is the population in the area affected by the quake event, and a set of country-specific attributes including technical knowledge $(T K)$ and experience stocks $(E X P)$, per capita income $(Y)$ and political institutions $(I) . X$ is a vector of variables measuring observed country characteristics including human capital, urbanization, trade openness, public health system, total population, land area and total patent applications by residents, which are to control for a country's overall vulnerability to disaster shocks and its science and technology base.

To avoid potential endogeneity, we lag all the country-level variables by one year (except for the land area, which is time-invariant). Following the

${ }^{1}$ Also note that this conceptual model focuses on a closed economy and does not include foreign knowledge, although we include our investigation of foreign knowledge in the results section. 
approach in prior studies (Anbarci et al., 2005; Kahn, 2005), we include continent fixed effects to control for the geopolitical heterogeneity. It is important to note here that we do not use the country fixed-effects model here because the within-country variation in knowledge and experience stocks are insufficient to identify their effects on earthquake losses. Furthermore, as Kahn (2005) points out, adjustment in socio-economic conditions is unlikely to immediately improve the average quality of infrastructure. This is also true for the technological change, given the certain latency between the development of new protective technologies and their actual diffusion. Thus, we primarily rely on the cross-country variation for identification purposes, after controlling for a wide range of variables that reflect development and institutions. ${ }^{2}$ In the model, we also include the year fixed effects to account for time-varying factors that may affect all countries. Because the knowledge and experience stocks generally increase over time, having the year dummies can help rule out the possibility that the knowledge stocks only pick up other tendencies for earthquake damages to decrease over time. Moreover, we cluster standard errors at the country level to address potential heteroskedasticity.

Finally, it should be noted that our unit of observation is an earthquake event; therefore, we only include an observation when an event occurred in a country-year. ${ }^{3}$ Repeated country-year observations are included in the regression when the country experienced multiple events within the same year.

\section{Data and estimation}

\subsection{Patent data and technical knowledge}

To construct technical knowledge stocks, we use the data on patents filed in the earthquake-proof building technology from an online global patent database, Delphion.com. These patents are identified based on the International Patent Code (IPC). A majority of the identified patents are for seismic and structural engineering technologies such as damper device, vibration absorber, quake-immune curtain wall system and building collapse control systems. The appendix provides more details on our patent search strategy.

We construct a country's stock of technical knowledge in quake-proof buildings using patent counts based on the following formula (Popp, 2003;

${ }^{2}$ To date, very few studies have included country fixed effects to estimate the effect of a country's socio-economic conditions on its disaster losses. For example, Kellenberg and Mobarak (2008) use a fixed effects negative binomial model and find a nonlinear relationship between income and disaster fatalities. However, their approach does not truly control for unobserved country fixed effects. In another recent study, Ferreira et al. (2013) employ the Poisson fixed effects model with clustered standard errors to examine the effect of development on flood fatalities. They show that income has a significant but indirect effect on reducing fatalities in poor countries only, and little impact of improved governance on flood fatalities.

${ }^{3}$ We intentionally construct the data based on earthquake events to include the events with missing deaths (discussed in the data section). 
Popp et al., 2011):

$$
T K_{\mathrm{c}, t}=\sum_{S=0}^{\infty} \mathrm{e}^{-\beta_{1}(S)}\left(1-\mathrm{e}^{-\beta_{2}(S+1)}\right) P A T_{\mathrm{c}, t-s},
$$

where $\beta_{1}$ represents a rate of decay to capture the obsolescence of older patents, and $\beta_{2}$ represents the rate of diffusion to capture delays in the flow of knowledge. The rate of diffusion is multiplied by $(s+1)$ so diffusion is not constrained to be zero in the current period. $S$ is the number of years before the current year $t$. PAT represents the total count of unique quakeproof building-related patents filed in country $c$ during the period of $t-s$. We follow the convention in the literature by assuming a decay rate of 0.10 and a diffusion rate of 0.25 . $^{4}$

Two things are important to note here. First, although patents are a common and direct measure used in the innovation literature to track technological innovation, it is an imperfect measure because not all inventions get patented by inventors and the amount of patent applications is heavily influenced by a country's patent system. ${ }^{5}$ Therefore, it is important to include the total patent applications filed by a country's residents to control for the cross-country heterogeneity in patent institutions and a country's general propensity to patent. Secondly, our sample includes certain developing countries that do not have an established patent regime; for these countries, we coded their patent counts as zero.

\subsection{Country characteristics}

We collect data on real GDP per capita from the Penn World Table (7.0 version) to measure a country's income. We use the political rights variable from Freedom House as a proxy for the quality of political institutions, which takes a value from 1 to 7 , with higher values indicating fewer political rights in the country. Other country controls in this study include human capital (measured by mean years of schooling for adults aged 25 years and older), urbanization (percentage of people living in urban areas in a country), openness (average ratio of exports and imports of goods and services in GDP), and quality of the public health system (mortality rate of children under the age of five). To measure a country's patent system and the general propensity to patent inventions, we use the total number of patent applications filed within the country by its residents. All these data are drawn from the World Bank Development Indicators, except for

4 The parameters (the rates of decay and diffusion) used in this paper provide a lag peaking after four years, which is consistent with the length of lag structure for R\&D capital in the literature. For example, Griliches (1995) notes that most past studies suggest a structuring peaking between three and five years. We also use alternative diffusion rates $(0.2$ and 0.18$)$ in constructing knowledge stocks, and we find that they do not affect our estimates of the effect of knowledge stocks.

${ }^{5}$ Despite these limitations, we note that patent data seem the only choice available in this research given our focus on a specific type of technology. Data on other alternative measures, such as R\&D expenditure and engineers in technologyspecific fields, are generally unavailable for all countries. 
the human capital data, which we collect from United National Development Programme Human Development Reports. We control for a country's size using data on population from the Penn World Table and the land area from the Global Rural-Urban Mapping Project (GRUMP).

\subsection{Earthquake data}

The raw data on earthquake fatalities and physics are taken from the NGDC Significant Earthquake Database. This database includes an earthquake event if it meets at least one of these criteria: at least US\$1m damage was incurred; 10 or more people were killed; the earthquake had a magnitude 7.5 or greater or Modified Mercalli Intensity X or greater, or the earthquake generated a tsunami. ${ }^{6}$ Our dependent variable is earthquakeinduced fatalities, which are normalized using the inverse hyperbolic sine function (Pence, 2006) which approximates the logarithmic transformation in its right tail and allows for including observations with zero values $\left(\ln \left[\right.\right.$ deaths $\left.\left.+\left(\text { deaths }^{\wedge} 2+1\right)^{\wedge} 0.5\right]\right)$. We use the same approach to normalize knowledge and experience stocks for the ease of interpretation in percentage changes. ${ }^{7}$

Using the NGDC data set, we create an experience stock using the number of quakes above magnitude 5 that occurred since 1900 (Quake $c t$ ) based on the perpetual inventory model (PIM), assuming the experience stock depends on a distributed lag of the current and past events: ${ }^{8}$

$$
E X P_{c t}=\text { Quake }_{c t}+(1-\rho) E X P_{c t-1},
$$

where $\rho$ is the rate of stock depreciation, which is assumed to be 15 per cent based on the innovation literature (Coe and Helpman, 1995; Miao and Popp, 2014). ${ }^{9}$ As we discussed earlier, using PIM, which discounts earlier shocks and assigns more weight to more recent earthquakes, distinguishes our study from previous research that assumes constant tendency to adapt.

An earthquake can cause significant damages when it occurs in a heavily populated area. To measure the size of the population exposed to individual quakes, we use the coordinates information for earthquake locations provided by the NGDC database to calculate the number of people living

6 The NGDC earthquake data are compiled from multiple sources, including the US Geological Survey, EM-DAT, reconnaissance reports, regional and local earthquake catalogs, newspapers and journal articles.

7 We also used the logarithmic transformation of deaths using $\ln ($ deaths +1$)$ to smooth data and keep observations with zero deaths. We find our results are almost the same as those estimated with the inverse hyperbolic sine function.

${ }^{8}$ We choose magnitude 5 as the threshold because earthquakes that measure 5 on the Richter scale can cause moderate damages. We also use magnitude 6 as an alternative threshold in creating the cumulative experience stocks, and we find our estimation results are robust to the alternative measure of experience stock.

${ }^{9}$ For robustness check we create alternative measures of experience stocks assuming $\rho=0.1$ and $\rho=0.2$. We find that our results are robust to using different values of the depreciation rate. 
within a $100 \mathrm{~km}$ radius around the epicenter using the Gridded Population of the World (GPW) spatial population data. ${ }^{10}$

One problem with the NGDC database is that a considerable proportion of the earthquake events recorded by NGDC have missing values for fatalities and monetary damages. ${ }^{11}$ Specifically, nearly 55 per cent of the earthquakes in our sample countries do not have information on deaths; the reasons for the missing data are as follows: (1) Coding error - when an earthquake caused no deaths, it is coded as missing rather than zero; therefore, the NGDC data do not have any events coded with zero deaths or damages; and (2) truly missing. There is no information available about the exact losses. ${ }^{12}$ Note that this issue is not specific to the NGDC data set, but is essentially common in other disaster databases such as the EMDAT. $^{13}$ If the data on the dependent variable are missing completely at random (i.e., the probability of having missing values is neither dependent on other observed variables nor the on value of the variable itself), the analysis should still provide unbiased estimates. However, the missing data are not random here because the missing values include earthquakes that resulted in zero deaths or damages (but we do not know exactly which portion of the missing data are true zeros or truly missing); moreover, we find that lower intensity earthquakes are more likely to have missing values on deaths and damages. This suggests the mechanism that generates missing data could that be these earthquakes caused very few losses, which are therefore unreported. In other words, the missingness depends on the value of our outcome variable itself.

\subsection{Estimation}

The issue of missing data on disaster damages has rarely been dealt with seriously in previous studies, and most researchers treated missing deaths as zero, especially when they collapsed events to the country-year observations. Because the NGDC's missing data do include zero deaths and are also associated with smaller and less destructive earthquakes, it seems relatively safe to assume that these missing values may indicate very few deaths. Therefore, we begin with the strongest assumption (i.e., missing is zero) and estimate equation (4) using an ordinary least squares (OLS) and

10 This procedure is done using the ArcMAP by intersecting the population data with the earthquake event layer. We used the population data of 1995 and interpolated the annual data on the local population exposure variable based on a country's average population growth.

${ }^{11}$ In this paper, we use fatalities only as the measure of earthquake losses. Although the NGDC also contains data on monetary damage, an even higher proportion of earthquakes has missing values on dollar damages compared to those with missing deaths, which made the damage data less reliable for use.

12 These explanations were provided by the NGDC data manager, Paula Dunbar, through personal communication.

13 On its website, the EM-DAT states that ' 0 ' does not represent a value and can mean no information available. 
Tobit model. ${ }^{14}$ We then relax this assumption by left censoring all the missing deaths at 10 , because 10 deaths is one of the thresholds for including an earthquake in the NGDC database. ${ }^{15}$ Under this assumption, we estimate the same equation using a censored normal regression, which is one variation of the Tobit model. ${ }^{16}$

Finally, we use the Heckman selection model (Heckman, 1979) to first predict the events that have non-missing deaths and then model the earthquake fatalities in the second stage. ${ }^{17}$ One advantage of using a selection model is that it does not involve any imputation of the missing values. To model the first-stage selection process, we use a tsunami indicator (a binary variable coded as 1 if the earthquake has generated a tsunami and 0 otherwise) as an instrumental variable. Recall that the occurrence of a tsunami is one of the criteria for including an earthquake in the NGDC database. In particular, there are a considerable number of earthquakes in this database that were tsunamigenic but with no information on their actual impacts. Therefore, the tsunami indicator qualifies as an instrument because, as a criterion imposed by data collectors, it affects the selection process by bringing in many non-destructive events with missing deaths. Moreover, it does not directly correlate with our dependent variable, which includes direct deaths from earthquakes only. ${ }^{18}$

\subsection{Sample and descriptive statistics}

Considering the fact that small-scale earthquakes may cause only minor damages (Keefer et al., 2011; Neumayer et al., 2014), we limit our sample to earthquakes of magnitude 5 and above. Our study sample includes a total of 894 earthquakes that occurred in 79 countries over the period 19802010. We choose 1980 as the starting year to allow the accumulation of knowledge stocks before entering the regression because the patent data generally became available in the mid-1970s.

${ }^{14}$ Because the earthquake deaths and damages can never be negative, this 'corner solution situation' generally renders OLS inappropriate as an estimation methodology and makes a Tobit estimator preferable (Wooldridge, 2006).

15 Note that this approach assumes all the events with missing deaths have killed no more than 10 people. It is more conservative to use a wider range ( $<10$ deaths) than to assign a specific value (zero).

16 We estimate the model using the 'cnreg' command in Stata.

17 Specifically, the first stage is run on the full sample of earthquake events using a Probit model, and models the events that have non-missing deaths, considering that this group is systematically different from the group with missing deaths. The second stage, the conditional equation, is an OLS model run only on the events with non-missing deaths and also includes a variable, the inverse Mills ratio, which is obtained in the first stage and controls for selection into this subsample. The Heckman selection model imposes exclusion restrictions, which means that we need to identify an instrument variable that determines the probability of having missing values but does not directly affect the earthquake losses.

18 The NGDC distinguishes the losses from earthquakes directly and losses from the secondary effect of earthquakes such as tsunamis. 
Table 1. Earthquake and patent statistics for sample nations

\begin{tabular}{|c|c|c|c|c|c|c|c|}
\hline Country & $\begin{array}{l}\text { \# of } 5+ \\
\text { quakes }\end{array}$ & $\begin{array}{l}\text { Total deaths } \\
\text { (persons) }\end{array}$ & $\begin{array}{c}\text { \# of } \\
\text { patents }\end{array}$ & Country & $\begin{array}{l}\text { \# of } 5+ \\
\text { quakes }\end{array}$ & $\begin{array}{l}\text { Total deaths } \\
\text { (persons) }\end{array}$ & $\begin{array}{l}\text { \# of } \\
\text { patents }\end{array}$ \\
\hline Afghanistan & 26 & 9,204 & 0 & Jordan & 1 & 0 & 0 \\
\hline Albania & 3 & 0 & 0 & Kazakhstan & 1 & 1 & 0 \\
\hline Algeria & 10 & 7,509 & 0 & Kyrgyzstan & 8 & 131 & 0 \\
\hline Argentina & 5 & 9 & 10 & Laos & 1 & 0 & 0 \\
\hline Armenia & 1 & 0 & 0 & Lebanon & 1 & 0 & 0 \\
\hline Australia & 4 & 12 & 12 & Macedonia & 3 & 1 & 0 \\
\hline Austria & 1 & 1 & 7 & Malawi & 3 & 13 & 0 \\
\hline Azerbaijan & 2 & 32 & 0 & Mexico & 27 & 9,962 & 10 \\
\hline Bangladesh & 4 & 5 & 0 & Morocco & 1 & 628 & 0 \\
\hline Belgium & 1 & 2 & 8 & Mozambique & 1 & 4 & 0 \\
\hline Bhutan & 5 & 11 & 0 & Nepal & 3 & 1,291 & 0 \\
\hline Bolivia & 1 & 105 & 0 & Netherlands & 1 & 1 & 11 \\
\hline Bulgaria & 1 & 3 & 8 & New Zealand & 17 & 3 & 29 \\
\hline Canada & 2 & 0 & 35 & Nicaragua & 4 & 7 & 0 \\
\hline Chile & 27 & 605 & 0 & Pakistan & 16 & 86,556 & 0 \\
\hline China & 94 & 92,072 & 291 & Panama & 8 & 2 & 0 \\
\hline Colombia & 11 & 1551 & 0 & $\begin{array}{c}\text { Papua New } \\
\text { Guinea }\end{array}$ & 20 & 87 & 0 \\
\hline $\begin{array}{l}\text { Congo, Dem. } \\
\text { Rep. }\end{array}$ & 4 & 54 & 0 & Peru & 26 & 853 & 0 \\
\hline Costa Rica & 9 & 130 & 0 & Philippines & 28 & 2,685 & 0 \\
\hline Croatia & 1 & 0 & 0 & Portugal & 4 & 79 & 0 \\
\hline Cuba & 1 & 0 & 0 & $\begin{array}{l}\text { Republic of } \\
\text { Korea }\end{array}$ & 1 & 0 & 217 \\
\hline Cyprus & 1 & 2 & 0 & Romania & 7 & 18 & 23 \\
\hline $\begin{array}{r}\text { Dominican } \\
\text { Republic }\end{array}$ & 2 & 8 & 0 & Russia & 14 & 2,018 & 79 \\
\hline Ecuador & 10 & 1,050 & 0 & Saudi Arabia & 1 & 0 & 0 \\
\hline Egypt & 3 & 557 & 0 & Slovenia & 1 & 1 & 0 \\
\hline El Salvador & 5 & 2,303 & 0 & $\begin{array}{l}\text { Solomon } \\
\text { Islands }\end{array}$ & 15 & 55 & 0 \\
\hline Ethiopia & 2 & 0 & 0 & South Africa & 1 & 15 & 0 \\
\hline Fiji & 5 & 5 & 0 & Sudan & 3 & 33 & 0 \\
\hline France & 1 & 0 & 134 & Tajikistan & 5 & 68 & 0 \\
\hline Georgia & 1 & 0 & 0 & Tanzania & 2 & 2 & 0 \\
\hline Greece & 29 & 218 & 31 & Thailand & 1 & 0 & 0 \\
\hline Guatemala & 9 & 33 & 0 & Tonga & 1 & 0 & 0 \\
\hline Haiti & 2 & 222,574 & 0 & $\begin{array}{l}\text { Trinidad and } \\
\text { Tobago }\end{array}$ & 3 & 1 & 0 \\
\hline Honduras & 4 & 12 & 0 & Turkey & 39 & 20,442 & 0 \\
\hline Iceland & 3 & 0 & 0 & Turkmenistan & 1 & 11 & 0 \\
\hline India & 27 & 33,217 & 0 & Uganda & 1 & 7 & 0 \\
\hline Indonesia & 107 & 11,742 & 0 & United States & 59 & 149 & 323 \\
\hline Iran & 74 & 81,214 & 0 & Vanuatu & 14 & 5 & 0 \\
\hline Italy & 15 & 5,060 & 42 & Venezuela & 10 & 98 & 0 \\
\hline Japan & 65 & 5,769 & 9,928 & & & & \\
\hline
\end{tabular}

Notes: While the earthquake counts and impact data cover the period 1980-2010, my patent data reflect the total counts of patent applications filed between 1974 and 2009 . 
Table 1 provides the national summary statistics reporting the sampled country's total earthquake counts, total earthquake-related deaths and total counts of patents in quake-proof building technologies over our study period. Notably, 17 countries out of the sample have patents in the given technology field, and among all the patenting countries, Japan, the United States, China and the Republic of Korea have filed the most patent applications. ${ }^{19}$ Table 2 reports the descriptive statistics of the main variables used in this research.

\section{Results}

\subsection{The effect of domestic knowledge}

Table 3 presents the regression results for equation (4) using different estimation strategies, which provide strong and consistent evidence that both the technical knowledge and experience stocks have statistically significant and negative correlations with earthquake fatalities. The estimated coefficients indicate that, all else constant, a 10 per cent increase in the patent knowledge stock is on average associated with a 1.9-3.9 per cent decrease in expected earthquake fatalities, and a 10 per cent increase in the experience stock is associated with a 3.4-5.6 per cent decrease in expected fatalities. Notably, using the Tobit model and Heckman selection model yields slightly higher estimated coefficients for knowledge and experience stocks relative to the other two models.

As discussed earlier, in this paper we create the experience stock using a PIM model, which assigns more weight to more recent earthquake events to account for learning from disasters. To compare the effect of our timevarying experience stock variable with the summed historic earthquake frequency used in prior studies (Anbarci et al., 2005; Keefer et al., 2011; Neumayer et al., 2014), we include both such variables in the same regressions. In the results available upon request, we find that the estimated coefficient for the earthquake experience stocks remains significant, while the time-invariant frequency measure is overall insignificant. This finding suggests the stronger explanatory power of the weighted past experiences for current earthquake losses, and also provides support for our conceptual argument that adapting to natural disasters is a dynamic process involving both knowledge updating and depreciation.

All the quake-related variables (magnitude, focal depth, and population exposed to individual earthquakes) are statistically significant for explaining fatalities, and have the expected sign. With respect to other socio-economic controls at the country level, we find that income has little

19 Japan has significantly more patents than other countries because its patent systems require inventors to file multiple patents for the same invention that would be covered by a single patent in other countries. This suggests the importance of controlling for a country's patent institutions as we have done in this study. Also note that, despite the substantial variation across countries in their earthquake patents, we do not use patent counts directly as an independent variable. Instead, we compute the knowledge stock based on patent counts and normalize the stock variable to alleviate the concerns regarding outliers. 
Table 2. Main variables and descriptive statistics

\begin{tabular}{|c|c|c|c|c|c|c|}
\hline Definition & Data sources & Operational variables & Mean & $S D$ & Min & $\operatorname{Max}$ \\
\hline Earthquake losses & NGDC & Earthquake fatalities $^{b}$ & 1.519 & 2.259 & 0 & 13.006 \\
\hline Past earthquake experiences & NGDC & Experience stocks (EXP) $)^{a, b}$ & 2.437 & 1.137 & 0 & 4.324 \\
\hline $\begin{array}{l}\text { Patent knowledge stock in } \\
\text { quake-proof building } \\
\text { technologies }\end{array}$ & Delphion.com & $\begin{array}{l}\text { Domestic knowledge stocks } \\
\qquad(\mathrm{TK})^{a, b}\end{array}$ & 1.249 & 2.097 & 0 & 7.966 \\
\hline Foreign patent knowledge stock & Delphion.com & Foreign knowledge stocks (FTK) ${ }^{b}$ & 1.95 & 0.675 & 0.263 & 3.763 \\
\hline Earthquake magnitude & NGDC & Magnitude (Richter scale) & 6.241 & 0.817 & 5 & 9.1 \\
\hline Earthquake magnitude & NGDC & Focal depth $(\mathrm{km})$ & 31.693 & 53.941 & 0 & 675 \\
\hline Population exposure & $\begin{array}{l}\text { NGDC, Gridded Population of } \\
\text { the World (GPW) }\end{array}$ & $\log (\text { exposed population })^{b}$ & 19.621 & 3.414 & 0 & 24.255 \\
\hline Income & World Bank & $\log (\text { GDP per capita })^{a}$ & 8.665 & 1.072 & 5.231 & 10.692 \\
\hline Political institution & Freedom House & Political rights $^{a}$ & 3.408 & 2.152 & 1 & 7 \\
\hline Country population & Penn World Table & $\log (\text { population })^{a}$ & 17.859 & 2.025 & 11.545 & 21.004 \\
\hline Urbanization & World Bank & Percent of urban population (\%) & 53.854 & 21.708 & 5.839 & 95.601 \\
\hline Human capital & $\begin{array}{l}\text { UNDP Human Development } \\
\text { Reports }\end{array}$ & $\begin{array}{l}\text { Mean years of schooling for } \\
\text { adults aged } 25 \text { years and older }\end{array}$ & 7.053 & 2.834 & 0.6 & 12.9 \\
\hline Public health & World Bank & $\begin{array}{l}\text { Mortality rate of children under } \\
\text { the age of five }(\%)^{a}\end{array}$ & 4.357 & 3.535 & 0.29 & 23.44 \\
\hline Openness & World Bank & $\begin{array}{l}\text { Average ratio of exports and } \\
\text { imports of goods and services } \\
\text { in GDP }(\%)^{a}\end{array}$ & 26.047 & 12.974 & 6.173 & 82.692 \\
\hline Patent institution & World Bank & $\begin{array}{l}\log (\text { residents-filed patent } \\
{\text { applications })^{b}}^{b}\end{array}$ & 6.142 & 3.747 & 0 & 12.859 \\
\hline Land area & $\begin{array}{l}\text { Global Rural-Urban Mapping } \\
\text { Project }\end{array}$ & $\log ($ area $)$ & 13.702 & 1.739 & 6.498 & 16.630 \\
\hline
\end{tabular}

Notes: ${ }^{a}$ Variables are one-year lagged. ${ }^{b}$ Variables are normalized using the inverse hyperbolic sine function (Pence, 2006). 
Table 3. Modeling the effect of domestic knowledge on earthquake fatalities

\begin{tabular}{|c|c|c|c|c|}
\hline Independent variables & $\begin{array}{l}(1) \\
\text { OLS }\end{array}$ & $\begin{array}{l}(2) \\
\text { Tobit }\end{array}$ & Censored normal & $\begin{array}{c}(4) \\
\text { Selection }\end{array}$ \\
\hline $\operatorname{EXP}(t-1)$ & $\begin{array}{l}-0.339^{* * *} \\
(0.0966)\end{array}$ & $\begin{array}{l}-0.441^{* *} \\
(0.172)\end{array}$ & $\begin{array}{l}-0.399^{* * *} \\
(0.109)\end{array}$ & $\begin{array}{l}-0.559^{* * *} \\
(0.203)\end{array}$ \\
\hline $\mathrm{TK}(t-1)$ & $\begin{array}{r}-0.187^{* *} \\
(0.0724)\end{array}$ & $\begin{array}{l}-0.393^{* * *} \\
(0.133)\end{array}$ & $\begin{array}{l}-0.225^{* * *} \\
(0.082)\end{array}$ & $\begin{array}{r}-0.294^{*} \\
(0.173)\end{array}$ \\
\hline Magnitude & $\begin{array}{l}1.421^{* * *} \\
(0.186)\end{array}$ & $\begin{array}{l}2.610^{* * * *} \\
(0.241)\end{array}$ & $\begin{array}{l}1.890^{* * *} \\
(0.217)\end{array}$ & $\begin{array}{l}2.819^{* * *} \\
(0.429)\end{array}$ \\
\hline Focal depth & $\begin{array}{l}-0.00371^{* * *} \\
(0.00116)\end{array}$ & $\begin{array}{c}-0.0138^{* * *} \\
(0.00404)\end{array}$ & $\begin{array}{l}-0.00959^{* * *} \\
(0.00250)\end{array}$ & $\begin{array}{c}-0.0133^{* * *} \\
(0.00399)\end{array}$ \\
\hline $\begin{array}{l}\log (\text { exposed } \\
\text { population })\end{array}$ & $\begin{array}{l}0.174^{* * *} \\
(0.0333)\end{array}$ & $\begin{array}{l}0.557^{* * *} \\
(0.133)\end{array}$ & $\begin{array}{l}0.366^{* * *} \\
(0.0851)\end{array}$ & $\begin{array}{l}0.552^{* * *} \\
(0.118)\end{array}$ \\
\hline$\underset{(t-1)}{\log (\text { GDP per capita) }}$ & $\begin{array}{c}0.838 \\
(1.325)\end{array}$ & $\begin{array}{l}0.687 \\
(2.368)\end{array}$ & $\begin{array}{c}1.617 \\
(1.494)\end{array}$ & $\begin{array}{l}2.403 \\
(2.470)\end{array}$ \\
\hline $\begin{array}{l}{[\log (\text { GDP per capita })]^{2}} \\
(t-1)\end{array}$ & $\begin{array}{r}-0.0309 \\
(0.0805)\end{array}$ & $\begin{array}{c}-0.0140 \\
(0.148)\end{array}$ & $\begin{array}{r}-0.0807 \\
(0.0944)\end{array}$ & $\begin{array}{c}-0.128 \\
(0.150)\end{array}$ \\
\hline Political rights $(t-1)$ & $\begin{array}{r}0.143^{* *} \\
(0.0607)\end{array}$ & $\begin{array}{l}0.236^{* *} \\
(0.111)\end{array}$ & $\begin{array}{c}0.141^{*} \\
(0.0770)\end{array}$ & $\begin{array}{l}0.236^{* *} \\
(0.102)\end{array}$ \\
\hline $\log$ (population) $(t-1)$ & $\begin{array}{c}0.215 \\
(0.168)\end{array}$ & $\begin{array}{c}0.241 \\
(0.329)\end{array}$ & $\begin{array}{c}0.105 \\
(0.216)\end{array}$ & $\begin{array}{c}0.104 \\
(0.273)\end{array}$ \\
\hline Human capital $(t-1)$ & $\begin{array}{c}-0.0712 \\
(0.0661)\end{array}$ & $\begin{array}{c}-0.0346 \\
(0.131)\end{array}$ & $\begin{array}{c}-0.0686 \\
(0.0798)\end{array}$ & $\begin{array}{r}-0.0727 \\
(0.113)\end{array}$ \\
\hline Urbanization $(t-1)$ & $\begin{array}{c}0.00803 \\
(0.00954)\end{array}$ & $\begin{array}{c}0.00984 \\
(0.0174)\end{array}$ & $\begin{array}{l}0.00608 \\
(0.0120)\end{array}$ & $\begin{array}{c}0.0101 \\
(0.0170)\end{array}$ \\
\hline Health $(t-1)$ & $\begin{array}{c}0.0871 \\
(0.0524)\end{array}$ & $\begin{array}{r}0.192^{* *} \\
(0.0813)\end{array}$ & $\begin{array}{r}0.0867^{*} \\
(0.0524)\end{array}$ & $\begin{array}{c}0.149 \\
(0.0908)\end{array}$ \\
\hline Openness $(t-1)$ & $\begin{array}{l}-0.0140^{*} \\
(0.00745)\end{array}$ & $\begin{array}{r}-0.0103 \\
(0.0173)\end{array}$ & $\begin{array}{l}-0.0152 \\
(0.00969)\end{array}$ & $\begin{array}{r}-0.0239 \\
(0.0164)\end{array}$ \\
\hline $\begin{array}{l}\log (\text { patent applications }) \\
(t-1)\end{array}$ & $\begin{array}{c}0.0265 \\
(0.0596)\end{array}$ & $\begin{array}{c}0.0894 \\
(0.113)\end{array}$ & $\begin{array}{c}0.0327 \\
(0.0677)\end{array}$ & $\begin{array}{c}0.0764 \\
(0.110)\end{array}$ \\
\hline $\log ($ area $)$ & $\begin{array}{r}-0.0743 \\
(0.168)\end{array}$ & $\begin{array}{c}0.0354 \\
(0.284)\end{array}$ & $\begin{array}{c}0.0754 \\
(0.206)\end{array}$ & $\begin{array}{c}0.0546 \\
(0.227)\end{array}$ \\
\hline Constant & $\begin{array}{c}-17.42^{* * * *} \\
(5.939)\end{array}$ & $\begin{array}{l}-36.52^{* * *} \\
(11.18)\end{array}$ & $\begin{array}{l}-27.04^{* * * *} \\
(6.906)\end{array}$ & $\begin{array}{l}-41.07^{* * * *} \\
(12.56)\end{array}$ \\
\hline $\begin{array}{l}\text { Left censored } \\
N\end{array}$ & 894 & $\begin{array}{l}465 \\
894\end{array}$ & $\begin{array}{l}465 \\
894\end{array}$ & 894 \\
\hline
\end{tabular}

Notes: All the models include continent fixed effects, and year fixed effects, with robust standard errors clustered at the country level. ${ }^{* * *} p<0.01{ }^{* *} p<0.05$; $* p<0.1$.

impact on earthquake fatalities, which seems to contradict the prior finding that rich countries are better adapted to natural disasters and suffer fewer losses than poor countries. Note that in all models we include the logged GDP per capita and its squared term to allow for the nonlinear relationship between income and earthquake fatalities, as suggested by Kellenberg and Mobarak (2008). The estimated coefficients on both variables are statistically insignificant, and an F-test also shows that these two variables are not 
jointly significant. ${ }^{20}$ Interestingly, we find that the GDP variables become statistically significant and exhibit the similar inverse U-shaped relationship with fatalities as found in Kellenberg and Mobarak (2008), if we remove the knowledge stock variable, which presumably correlates with a country's income level (in the appendix). In other words, the inclusion of knowledge stocks has actually lowered the explanatory power of income for earthquake fatalities. We believe this comparison empirically confirms the importance of risk-mitigating innovation and knowledge accumulation as a separate mechanism for reducing disaster losses and provides a plausible explanation for why economic development can mitigate natural disaster fatalities.

With respect to other country characteristics, we find that countries with greater political rights suffer significantly fewer deaths from earthquakes, which resonates with prior findings in disaster research (e.g., Kahn, 2005; Toya and Skidmore, 2007; Keefer et al., 2011). Another variable that is statistically significant (or marginally significant) in multiple specifications is child mortality rate, with a positive estimated effect. This suggests that earthquakes of the same intensity result in more fatalities in countries with poorer public health systems. None of the previous studies has examined this factor, and we believe that the effect of health conditions on disaster risk deserves more attention in future empirical research in this field. ${ }^{21}$

Prior research suggests that developing and developed nations differ in their capacity to adapt to natural disasters, and disaster losses are less responsive to past hazard exposure in poor nations (Keefer et al., 2011). In this research, we take a further step to examine whether technical innovation explains why developed countries are better adapted conditioning on the same level of disaster experiences or risk exposure. In table 4, Panel A, we first follow Keefer et al. (2011) by interacting the experience stocks with two binary variables indicating developed countries and developing countries (using the World Bank 2009 classification), respectively, which allows for estimating the effects of experience stocks separately for the two country groups. Without accounting for the knowledge stocks, we are able to replicate the finding of Keefer et al. (2011) that increasing experience stocks reduce earthquake fatalities in both rich and poor countries, but with a larger effect in rich countries. Moreover, we find that the estimated coefficients of the two interaction terms are significantly different from one another in all specifications. This suggests that developed countries are generally more responsive to their past earthquake experiences and that they have stronger adaptive capacity in translating their experiences into more effective protection against subsequent disaster shocks.

In table 4, Panel B, we show that with the inclusion of knowledge stocks, the effect of prior earthquake experiences becomes no longer significant

${ }^{20}$ We also estimate the regression using the linear per capita GDP only, and find that the variable is statistically insignificant.

${ }^{21}$ In all regressions, we control for continent fixed effects and omit Africa as the baseline category. Here we do not report the estimated coefficients on the continent dummies (most of which are statistically insignificant) to keep the brevity of our results. 
Table 4. Interacting experience with developed and developing country dummies

\begin{tabular}{lcccc}
\hline Independent variables & $(1)$ & $(2)$ & $(3)$ & $(4)$ \\
\hline Panel $A$ & OLS & Tobit & Censored normal & Selection \\
Developed $\times$ EXP $(t-1)$ & $-0.57^{* *}$ & $-0.932^{* * *}$ & $-0.71^{* * *}$ & $-1.012^{* * *}$ \\
& $(0.153)$ & $(0.316)$ & $(0.181)$ & $(0.294)$ \\
Developing $\times$ EXP $(t-1)$ & $-0.274^{* * *}$ & $-0.325^{*}$ & $-0.331^{* * *}$ & $-0.442^{* * *}$ \\
& $(0.105)$ & $(0.171)$ & $(0.118)$ & $(0.189)$ \\
Test the equality of the two & 0.051 & 0.054 & 0.038 & 0.036 \\
$\quad$ coefficients $($ prob $>F)$ & & & & 894 \\
$N$ & 894 & 894 & 894 & 894 \\
Panel B & & & & -0.492 \\
Developed $\times$ EXP $(t-1)$ & $-0.372^{* * *}$ & -0.517 & -0.68 \\
& $(0.155)$ & $(0.375)$ & $(0.334)$ & $(0.360)$ \\
Developing $\times$ EXP $(t-1)$ & $-0.324^{* * *}$ & $-0.421^{* *}$ & $-0.379^{* * *}$ & $-0.522^{* *}$ \\
Test the equality of the two & $(0.0986)$ & $(0.164)$ & $(0.110)$ & $(0.217)$ \\
$\quad$ coefficients $($ prob $>F)$ & 0.754 & 0.793 & 0.623 & 0.648 \\
TK $(t-1)$ & $-0.189^{* *}$ & $-0.374^{* *}$ & $-0.194^{*}$ & $-0.331^{*}$ \\
$N$ & $(0.076)$ & $(0.152)$ & $(0.108)$ & $(0.180)$ \\
$N$ & 894 & 894 & 894 & 894 \\
\hline
\end{tabular}

Notes: All the models include continent fixed effects and year fixed effects, with robust standard errors clustered at the country level. All the specifications include all the other control variables. ${ }^{* * *} p<0.01 ;{ }^{* *} p<0.05 ;{ }^{*} p<0.1$.

in most specifications, while the same effect remains largely the same for developing countries. This result is not surprising because developed countries have more patented innovations, which make the interacted term with the developed country dummy highly correlate with the knowledge stock variable. Notably, the estimated coefficients on knowledge stocks are still significant and negative, although their significance declines slightly compared to the results in table 3. Based on the results in Panels A and $\mathrm{B}$, we infer that technological innovation serves as one important channel through which rich countries learn from their previous disaster experiences and adapt to future natural disaster risks.

As noted earlier, in this paper we primarily rely on the cross-country variation to identify the effects of knowledge and experience stocks on earthquake fatalities, and our empirical strategy does not control for the unobserved country characteristics. In the results presented in the appendix, we estimate both the country random effects (RE) and country fixed effects (FE) models using OLS and clustered standard errors. We observe that the RE estimated coefficients on both experience and knowledge stocks remain statistically significant, with their magnitude similar to our baseline estimates, whereas the FE estimators on both variables become insignificant, largely because of the insufficient within-country variation. However, we note that the magnitudes of the FE estimators do not differ much from our baseline estimates, only with increased standard errors. We 
also performed a Hausman test to compare the FE and RE estimates and found no significant differences between the two models. ${ }^{22}$

\subsection{The effect of foreign knowledge stocks}

Because our baseline results indicate that countries that have accumulated more technical knowledge in earthquake-proof building suffer fewer fatalities, we take a further step by asking whether one country's technical innovations benefit other countries in reducing their own disaster risks, considering the public good nature of knowledge and technical innovation. To investigate the possibility of international knowledge spillovers, we estimate equation (4) by including the variable of foreign knowledge stocks, which is calculated using equation (5) with the counts of foreign patents available to a country (i.e., total global patents minus the country's own patents in a given year). Because the cross-country heterogeneity in patent systems makes it problematic to value each patent equally, we weight patent counts by their patent family size following Popp et al. (2011), before calculating the foreign knowledge stocks. ${ }^{23}$

It should be noted that the foreign knowledge stock is, by construction, more or less the same for all countries, because each of them only contributes a relatively small number of patents to the global pool. In particular, the variable is equivalent to the global knowledge stocks for all non-patenting countries. However, countries may differ in their access to foreign technical innovations as well as their capacities to exploit foreign knowledge for reducing domestic disaster risks. In other words, the effect of foreign knowledge stocks could vary according to the characteristics of the recipient countries and the level of interaction between countries. The literature on international technology diffusion suggests knowledge spillovers are often likely to occur throughout international trade (Coe and Helpman, 1995). Therefore, in this paper we weight the foreign knowledge stocks by the bilateral trade flows, using the historic international trade data from CEPII (Fouquin and Hugot, 2016). Specifically, we calculated a weighted sum of foreign knowledge stock for each of the sampled countries in a given year by multiplying the bilateral trade weight (i.e., the bilateral trade flows as the percentage of a recipient country's total trade flow) with each trading country's own knowledge stock in earthquake-proof building technologies.

Moreover, we note that it always takes time for technical innovations to diffuse from one country to the other. Although we use one-year lagged values of the domestic knowledge stocks, it is reasonable to assume that the effect of foreign knowledge would take longer than one year to be realized. In table 5, Panel A, we report the estimation results based on equation (4) with the inclusion of foreign knowledge stocks, lagged by five years. We

${ }^{22}$ In addition, we also estimated the model excluding the large patenting countries (Japan, United States, China) in our concerned technological field and find that the knowledge stocks remain marginally significant, with almost no changes in their magnitudes.

23 The foreign knowledge stock variable is also normalized using the inverse hyperbolic sine function (Popp et al., 2011) before entering the regression. 
show that the estimated coefficients on foreign knowledge are negative but insignificant across all specifications, which provides little evidence on the mitigating effect of foreign knowledge. Also, note that including foreign knowledge stocks does not change the significance and magnitude of the estimated coefficients of domestic knowledge stocks. In results available on request, we have also conducted a set of sensitivity tests with alternative numbers of lags (three years and 10 years) and do not find any significant effect of foreign knowledge either. ${ }^{24}$

It is possible that countries more prone to earthquakes are more interested in introducing new quake-mitigating technologies that have been developed abroad. Their past earthquake 'endowment' may also enable them to better absorb and exploit foreign knowledge of mitigating earthquake risks. To examine the potential moderating effect of domestic earthquake experience, we add the interaction term between foreign knowledge stocks and a country's own experience stocks in table 5, Panel B. Again, our results do not provide any evidence on international knowledge spillovers or that past earthquake experiences moderate the effect of foreign technical knowledge. The estimated coefficients on both foreign knowledge stocks and the interaction terms are consistently insignificant across all specifications. The experience stock variables also lose their significance, largely due to multicollinearity.

These findings suggest that, compared to domestic knowledge stocks, foreign knowledge is less effective in reducing a country's disaster risk. This might be because the quake-proof building technologies are specific to local geography (Lanjouw and Mody, 1996) or that building and infrastructure construction is largely a local industry, both of which make it more difficult for these specific innovations to diffuse across countries.

Another reason that may cause the insignificance of foreign knowledge is multicollinearity, because the stock variable gradually increases over time and correlates with the year dummies. We also examine whether there has been a global downward trend in earthquake fatalities, if technologies, not necessarily limited to the quake-proof buildings but also other types of earthquake-mitigating measures (e.g., earthquake detection, early warning and debris removal), can gradually improve the adaptive capacity at the global scale.

In table 5, Panel $\mathrm{C}$, we re-estimate the models by replacing the foreign knowledge stock with linear and quadratic year trend variables, which account for the general global technological progress in mitigating earthquake impacts. We show that the time variables are still statistically insignificant, suggesting that in the past 30 years there has been no significant decrease in earthquake fatalities worldwide after controlling for country characteristics. This finding suggests disaster mitigation has, by

${ }^{24}$ In addition to weighting foreign knowledge by bilateral trade flows, we create alternative bilateral spatial weights following the approach in Aichele and Felbermayr (2012), which allows foreign knowledge stock to diminish with bilateral distances and increase with the origin country's population size. We still do not find any significant result using this measure. This may, in turn, suggest the robustness of our results. 
Table 5. Modeling the effect of foreign knowledge on earthquake fatalities

\begin{tabular}{|c|c|c|c|c|}
\hline Independent variables & $\begin{array}{l}(1) \\
\text { OLS }\end{array}$ & $\begin{array}{l}(2) \\
\text { Tobit }\end{array}$ & Censored normal & $\begin{array}{c}\text { (4) } \\
\text { Selection }\end{array}$ \\
\hline \multicolumn{5}{|c|}{ Panel A: Including foreign knowledge stocks weighted by bilateral trade flows } \\
\hline $\operatorname{EXP}(t-1)$ & $\begin{array}{l}-0.374^{* * *} \\
(0.102)\end{array}$ & $\begin{array}{c}-0.416^{* *} \\
(0.192)\end{array}$ & $\begin{array}{l}-0.381^{* * *} \\
(0.116)\end{array}$ & $\begin{array}{c}-0.515^{* *} \\
(0.248)\end{array}$ \\
\hline $\mathrm{TK}(t-1)$ & $\begin{array}{r}-0.182^{* *} \\
(0.0775)\end{array}$ & $\begin{array}{l}-0.374^{* *} \\
(0.145)\end{array}$ & $\begin{array}{r}-0.204^{* *} \\
(0.0877)\end{array}$ & $\begin{array}{c}-0.375^{* *} \\
(0.177)\end{array}$ \\
\hline $\operatorname{FTK}(t-5)$ & $\begin{array}{c}-0.0150 \\
(0.199)\end{array}$ & $\begin{array}{r}-0.498 \\
(0.385)\end{array}$ & $\begin{array}{l}-0.275 \\
(0.239)\end{array}$ & $\begin{array}{c}-0.591 \\
(0.473)\end{array}$ \\
\hline$N$ & 894 & 894 & 894 & 894 \\
\hline \multicolumn{5}{|c|}{ Panel B: Foreign knowledge interacted with own earthquake experience stocks } \\
\hline $\operatorname{EXP}(t-1)$ & $\begin{array}{c}-0.169 \\
(0.274)\end{array}$ & $\begin{array}{c}-0.093 \\
(0.470)\end{array}$ & $\begin{array}{c}-0.132 \\
(0.293)\end{array}$ & $\begin{array}{r}-0.291 \\
(0.459)\end{array}$ \\
\hline $\mathrm{TK}(t-1)$ & $\begin{array}{l}-0.174^{* * *} \\
(0.0777)\end{array}$ & $\begin{array}{l}-0.362^{* * *} \\
(0.147)\end{array}$ & $\begin{array}{l}-0.202^{* * *} \\
(0.0874)\end{array}$ & $\begin{array}{l}-0.378^{* *} \\
(0.177)\end{array}$ \\
\hline $\operatorname{FTK}(t-5) \times \operatorname{EXP}(t-1)$ & $\begin{array}{r}-0.0992 \\
(0.123)\end{array}$ & $\begin{array}{l}-0.168 \\
(0.213)\end{array}$ & $\begin{array}{c}-0.128 \\
(0.131)\end{array}$ & $\begin{array}{c}-0.115 \\
(0.194)\end{array}$ \\
\hline $\operatorname{FTK}(t-5)$ & $\begin{array}{c}0.220 \\
(0.336)\end{array}$ & $\begin{array}{c}-0.104 \\
(0.638)\end{array}$ & $\begin{array}{l}0.0226 \\
(0.359)\end{array}$ & $\begin{array}{r}-0.323 \\
(0.655)\end{array}$ \\
\hline$N$ & 894 & 894 & 894 & 894 \\
\hline \multicolumn{5}{|c|}{ Panel C: Replace foreign knowledge stocks with time trend variables } \\
\hline $\operatorname{EXP}(t-1)$ & $\begin{array}{c}-0.312^{* * *} \\
(0.0984)\end{array}$ & $\begin{array}{l}-0.386^{* *} \\
(0.180)\end{array}$ & $\begin{array}{l}-0.346^{* * *} \\
(0.117)\end{array}$ & $\begin{array}{l}-0.481^{* *} \\
(0.238)\end{array}$ \\
\hline $\operatorname{TK}(t-1)$ & $\begin{array}{l}-0.207^{* * *} \\
(0.0674)\end{array}$ & $\begin{array}{l}-0.416^{* * *} \\
(0.130)\end{array}$ & $\begin{array}{c}-0.246^{* * *} \\
(0.0778)\end{array}$ & $\begin{array}{l}-0.461^{* *} \\
(0.191)\end{array}$ \\
\hline Year trend & $\begin{array}{c}-0.00449 \\
(0.0381)\end{array}$ & $\begin{array}{c}-0.00056 \\
(0.0573)\end{array}$ & $\begin{array}{c}-0.0229 \\
(0.0426)\end{array}$ & $\begin{array}{r}-0.0231 \\
(0.0819)\end{array}$ \\
\hline Year trend`2 & $\begin{array}{c}0.0001 \\
(0.0011)\end{array}$ & $\begin{array}{c}-0.0008 \\
(0.00181)\end{array}$ & $\begin{array}{c}0.0006 \\
(0.00135)\end{array}$ & $\begin{array}{r}0.00005 \\
(0.00248\end{array}$ \\
\hline$N$ & 894 & 894 & 894 & 894 \\
\hline
\end{tabular}

Notes: Regressions in Panel A and B include continent dummies and year fixed effects, with robust standard errors clustered at the country level. Regressions in Panel C replace the year fixed effects with year trend and its square terms to examine the effect of global technological progress on earthquake fatalities. All regressions include all the other control variables. ${ }^{* *} p<0.01 ;{ }^{* *} p<0.05$.

far, relied more on the self-efforts of the affected countries than on external technological advancement.

\section{Conclusion}

Considerable work has been devoted in the past decade to understanding the determinants of the social impact of natural disasters. While the vast majority of the literature has focused on the aggregated impacts of income and institutions, little research has investigated the disaggregated effects of other development-related factors. Our paper fills this gap by considering 
knowledge as an important determinant of societal adaptation to natural disasters. Specifically, we make the first attempt to empirically examine the role of technical innovation in disaster risk mitigation by utilizing patent data to track the technological change in quake-proof buildings. Additionally, we account for a country's prior experiences with earthquakes, considering it as not only the motivation for adaptation, but also a measure of the unobserved informal knowledge enabling countries to better cope with earthquakes. Our results provide strong evidence that countries that have accumulated more innovations in quake-proof building technologies and greater exposure to past earthquakes suffer significantly fewer fatalities from later earthquakes. Moreover, we show that previous quake experiences result in a larger mitigating effect in developed countries than in developing countries and, more importantly, such a difference could be partially explained by the capacity of industrialized nations to develop new and better risk-mitigating technologies.

An important distinction between this study and prior research that examines disaster exposure is placing disaster mitigation within a learning framework, and using a PIM model to account for the post-disaster learning dynamics. Our finding not only provides a better understanding of what drives society to adapt to environmental changes and shocks, but also sheds light on adaptation as a dynamic learning process that involves behavioral biases. This research may further inform the modeling of potential future climate damages and climate adaptation (e.g., Bosello et al., 2009), because our results may suggest past experiences with climate variability and extreme weather events would motivate adaptation, which in turn reduces the future damages of climate change.

This paper also makes an important methodological contribution to the empirical natural hazard literature by addressing the issue of missing data on disaster fatalities and damages. Moreover, we use multiple estimation strategies to model earthquake fatalities, which produce consistent results across different specifications. Because the EM-DAT data that are most commonly used in current disaster research also have this data limitation, it is important for researchers to take this into account when making their choice of models and data structure. We expect this study to offer a starting point for more discussion and investigation of this specific empirical challenge.

Finally, our research has significant implications for disaster and climate adaptation policy at both the local and global levels. It highlights the importance of incorporating technology development into an integrated policy approach to mitigate natural hazard and climate risks. While the prior literature suggests that economic development and improvement in institutions provide 'implicit insurance' against natural disasters (Kahn, 2005), this research suggests that countries adjust their allocation of resources in investing mitigation-specific measures and put more effort into encouraging the development of risk-mitigating technologies. Although we do not find strong evidence on the spillover effect of foreign knowledge in this paper, this does not mean foreign knowledge does not matter. Given the highly localized nature of earthquakes, it is possible that countries rely more on their domestic knowledge in risk mitigation and 
have not yet fully exploited the technical innovations available abroad. If this is the case, one recommendation is that more policy efforts be made at the international level to encourage and facilitate technology diffusion and transfer of the risk-mitigating technologies across the world. Such policies will have important development implications and, in particular, provide benefits to developing countries that lack the capacity to innovate and adapt to natural disasters. Despite the insignificant finding from this study, there is some anecdotal evidence on the disaster-mitigating benefits associated with foreign knowledge spillovers. For example, the Maldives, an island nation in the Indian Ocean, was much less impacted by the 2004 Southeast Asian tsunami relative to other nations in that region such as Indonesia. This is partially because of the protection by a massive sea wall around the capital of Male, which was constructed with technology and assistance offered by the Japanese government (Toya and Skidmore, 2007). The potential role of technological development and diffusion in the global context deserves more investigation in future research.

\section{References}

Aichele, R. and G. Felbermayr (2012), 'Kyoto and the carbon footprint of nations', Journal of Environmental Economics and Management 64: 336-354.

Anbarci, N., M. Escaleras, and C.A. Register (2005), 'Earthquake fatalities: the interaction of nature and political economy', Journal of Public Economics 89: 1907-1933.

Atreya, A., S. Ferreira, and W. Kriesel (2013), 'Forgetting the flood? An analysis of the flood risk discount over time', Land Economics 89(4): 577-596.

Bakkensen, L.A. and R.O. Mendelsohn (2016), 'Risk and adaptation: evidence from global hurricane damages and fatalities', Journal of the Association of Environmental and Resource Economists 3(3): 555-587.

Barreca, A., K. Clay, O. Deschenes, M. Greenstone, and J.S. Shapiro (2016), 'Adapting to climate change: the remarkable decline in the U.S. temperature-mortality relationship over the twentieth century', Journal of Political Economy 124(1): 105-159, [Available at] http:/ / econpapers.repec.org/article/ucpjpolec/doi_3a10.1086_2f68 4582.htm.

Bosello, F., C. Carraro, and E. De Cian (2009), 'An analysis of adaptation as a response to climate change', Copenhagen Consensus Center, Copenhagen Business School, Copenhagen.

Coe, D. and E. Helpman (1995), 'International R\&D spillovers', European Economic Review 39: 859-887.

Cutter, S.L., B.J. Boruff, and W.L. Shirley (2003), 'Social vulnerability to environmental hazards', Social Science Quarterly 84: 242-261.

Escaleras, M. and C. Register (2016), 'Public sector corruption and natural hazards', Public Finance Review 44(6): 746-768.

Ferreira, S., K. Hamilton, and J.R. Vincent (2013), ‘Does development reduce fatalities from natural disasters? New evidence for floods', Environment and Development Economics 18(6): 649-679.

Fouquin, M. and J. Hugot (2016), 'Two centuries of bilateral trade and gravity data: 1827-2014', CEPII Working Paper, Paris.

Gallagher, J. (2014), 'Learning about an infrequent event: evidence from flood insurance take-up in the U.S.', American Economic Journal: Applied Economics 6(3): 206-233. 
Griliches, Z. (1995), ‘R\&D and productivity: econometric results and measurement issues', in P.L. Stoneman (ed.), Handbook of the Economics of Innovation and Technological Change, Cambridge, MA: Blackwell, pp. 52-89.

Heckman, J.J. (1979), 'Sample selection bias as a specification error', Econometrica 47(1): 153-161.

Hsiang, S.M. and D. Narita (2012), 'Adaptation to cyclone risk: evidence from the global cross-section', Climate Change Economics 3(2).

Kahn, M. (2005), 'The death toll from natural disasters: the role of income, geography and institutions', Review of Economics and Statistics 87(2): 271-284.

Keefer, P., E. Neumayer, and T. Plumper (2011), 'Earthquake propensity and the politics of mortality prevention', World Development 39(9): 1530-1541.

Kellenberg, D.K. and A.M. Mobarak (2008), 'Does rising income increase or decrease damage risk from natural disasters?', Journal of Urban Economics 63: 788-802.

Keller, W. (2001), 'International technology diffusion', NBER Working Paper No. 8573, Cambridge, MA.

Kousky, C. (2014), 'Informing climate adaptation: a review of the economic costs of natural disasters', Energy Economics 46: 576-592.

Kousky, C. (2016), 'Disasters as learning experiences or disasters as policy opportunities? Examining flood insurance purchases after hurricanes', Risk Analysis; doi:10.1111/risa.12646.

Lanjouw, J.O. and A. Mody (1996), 'Innovation and the international diffusion of environmentally responsive technology', Research Policy 25: 549-571.

Miao, Q. and D. Popp (2014), 'Necessity as the mother of invention: innovative responses to natural disasters', Journal of Environmental Economics and Management 68: 280-295.

National Science Board (2010), Science and Engineering Indicators 2010, Arlington, VA: National Science Foundation.

Neumayer, E., T. Plumper, and F. Barthel (2014), 'The political economy of natural disaster damage', Global Environmental Change 24: 8-19.

Pence, K.M. (2006), 'The role of wealth transformations: an application to estimating the effect of tax incentives on saving', BE Journal of Economic Analysis and Policy 5(1): 1-26.

Popp, D. (2003), 'Pollution control innovations and the Clean Air Act of 1990', Journal of Policy Analysis and Management 22(4): 641-660.

Popp, D., I. Hascic, and N. Medhi (2011), 'Technology and the diffusion of renewable energy', Energy Economics 33: 648-662.

Rashky, P. (2008), 'Institutions and the losses from natural disasters', Natural Hazards and Earth System Sciences 8: 627-634.

Sadowski, N.C. and D. Sutter (2008), 'Mitigation motivated by past experience: prior hurricanes and damages', Ocean \& Coastal Management 51: 303-313.

Schumacher, I. and E. Strobl (2011), 'Economic development and losses due to natural disasters: the role of hazard exposure', Ecological Economics 72: 97-105.

Stephan, P. (1996), 'The economics of science', Journal of Economic Literature 34(3): 1199-1235.

Toya H. and M. Skidmore (2007), 'Economic development and the impact of natural disasters', Economics Letters 94: 20-25.

United Nations International Strategy for Disaster Reduction (2009), 'Reducing disaster risks through science: issue and actions, the full report of the ISDR Scientific and Technical Committee 2009', [Available at] http:/ / www.unisdr.org/ files / 11543_STCReportlibrary.pdf.

Wooldridge, J. (2006), Introductory Econometrics: A Modern Approach, Mason, OH: Thomson, Couth-Western. 


\section{Appendix}

\section{Patent search codes}

In search of the quake-proof building patents, we used the following code on delphion.com:

$$
((\text { E04H 00902) <in > IC). }
$$

E04H 00902: Buildings, groups of buildings, or shelters, adapted to withstand or provide protection against, abnormal external influences (e.g. warlike action, earthquake, extreme climate) withstanding earthquake or sinking of ground.

Table A1. Regression results excluding domestic knowledge stocks

\begin{tabular}{lcccc}
\hline \multirow{2}{*}{ Independent variables } & $(1)$ & $(2)$ & $(3)$ & $(4)$ \\
& OLS & Tobit & Censored normal & Selection \\
\hline EXP $(t-1)$ & $-0.360^{* * *}$ & $-0.463^{* * *}$ & $-0.415^{* * *}$ & $-0.564^{* * *}$ \\
& $(0.0997)$ & $(0.177)$ & $(0.116)$ & $(0.189)$ \\
$\log ($ GDP per capita) $(t-1)$ & $2.473^{*}$ & $3.997^{*}$ & $3.149^{* *}$ & $4.688^{* *}$ \\
& $(1.284)$ & $(2.333)$ & $(1.366)$ & $(2.017)$ \\
{$[\log (\text { GDP per capita })]^{2}(t-1)$} & $-0.134^{*}$ & -0.225 & $-0.179^{* *}$ & $-0.276^{* *}$ \\
& $(0.0790)$ & $(0.149)$ & $(0.0865)$ & $(0.120)$ \\
Constant & $-23.72^{* * *}$ & $-48.81^{* * *}$ & $-32.68^{* * *}$ & $-48.12^{* * *}$ \\
& $(5.606)$ & $(10.37)$ & $(6.391)$ & $(12.08)$ \\
Left censored & & 465 & 465 & \\
& 894 & 894 & 894 & 894 \\
\hline
\end{tabular}

Notes: All the models include continent fixed effects and year fixed effects, with robust standard errors clustered at the country level. Note that by excluding the domestic knowledge stock variables, we find that the per capita GDP variables become statistically significant and exhibit an inverse U-shaped relationship with earthquake fatalities, which resonates with the findings in Kellenberg and Mobarak (2008). ${ }^{* * *} p<0.01 ;{ }^{* *} p<0.05 ;{ }^{*} p<0.1$. 
Table A2. OLS with country random effects and fixed effects

\begin{tabular}{|c|c|c|}
\hline Independent variables & $\begin{array}{c}\text { (1) } \\
\text { Random effects }\end{array}$ & $\begin{array}{c}\text { (2) } \\
\text { Fixed effects }\end{array}$ \\
\hline $\operatorname{EXP}(t-1)$ & $\begin{array}{c}-0.245^{* *} \\
(0.102)\end{array}$ & $\begin{array}{r}-0.210 \\
(0.247)\end{array}$ \\
\hline $\mathrm{TK}(t-1)$ & $\begin{array}{r}-0.197^{* *} \\
(0.0862)\end{array}$ & $\begin{array}{r}-0.200 \\
(0.211)\end{array}$ \\
\hline Magnitude & $\begin{array}{l}1.507^{* * *} \\
(0.190)\end{array}$ & $\begin{array}{l}1.621^{* * *} \\
(0.204)\end{array}$ \\
\hline Focal depth & $\begin{array}{l}-0.00391^{* * *} \\
(0.00111)\end{array}$ & $\begin{array}{r}-0.00412^{* * *} \\
(0.000994)\end{array}$ \\
\hline $\log ($ exposed population) & $\begin{array}{l}0.173^{* * *} \\
(0.0324)\end{array}$ & $\begin{array}{l}0.176^{* * *} \\
(0.0336)\end{array}$ \\
\hline $\log ($ GDP per capita) $(t-1)$ & $\begin{array}{l}1.093 \\
(1.125)\end{array}$ & $\begin{array}{l}1.746 \\
(2.352)\end{array}$ \\
\hline$[\log (\mathrm{GDP} \text { per capita })]^{2}(t-1)$ & $\begin{array}{r}-0.0488 \\
(0.0674)\end{array}$ & $\begin{array}{c}-0.113 \\
(0.159)\end{array}$ \\
\hline Political rights $(t-1)$ & $\begin{array}{c}0.0714 \\
(0.0645)\end{array}$ & $\begin{array}{r}-0.0259 \\
(0.0606)\end{array}$ \\
\hline $\log ($ population $)(t-1)$ & $\begin{array}{l}0.375^{* * *} \\
(0.124)\end{array}$ & $\begin{array}{l}-0.815 \\
(1.439)\end{array}$ \\
\hline Human capital $(t-1)$ & $\begin{array}{l}-0.0219 \\
(0.0681)\end{array}$ & $\begin{array}{l}-0.108 \\
(0.135)\end{array}$ \\
\hline Urbanization $(t-1)$ & $\begin{array}{l}0.0107 \\
(0.00809)\end{array}$ & $\begin{array}{c}0.0441 \\
(0.0349)\end{array}$ \\
\hline Health $(t-1)$ & $\begin{array}{l}0.146^{* * *} \\
(0.0497)\end{array}$ & $\begin{array}{l}0.157^{*} \\
(0.0925)\end{array}$ \\
\hline Openness $(t-1)$ & $\begin{array}{r}-0.00908 \\
(0.00851)\end{array}$ & $\begin{array}{r}-0.0179 \\
(0.0118)\end{array}$ \\
\hline $\log ($ patent applications $)(t-1)$ & $\begin{array}{l}0.00804 \\
(0.0589)\end{array}$ & $\begin{array}{r}-0.0316 \\
(0.0789)\end{array}$ \\
\hline $\log ($ area $)$ & $\begin{array}{r}-0.216 \\
(0.132)\end{array}$ & \\
\hline Constant & $\begin{array}{c}-20.58^{* * *} \\
(5.534)\end{array}$ & $\begin{array}{l}-4.764 \\
(24.26)\end{array}$ \\
\hline$N$ & 894 & 894 \\
\hline
\end{tabular}

Notes: Both regressions include year fixed effects, with robust standard errors clustered at the country level. The random effects model also includes continent dummies. Our results with the country random effects show that both experience stock and knowledge stock variables are statistically significant and negatively correlate with earthquake fatalities, which are consistent with the pooled cross-sectional estimation results. However, both variables become insignificant in the fixed effects model, because of the insufficient withincountry variation. However, it should be noted that the estimated coefficients on both experience and knowledge stock do not differ much between the two models, while the standard errors increase substantially in the fixed effects model. We have also performed the Hausman test, which shows no significant difference between the RE and FE estimators. ${ }^{* *} p<0.01$; ${ }^{* *} p<0.05 ;{ }^{*} p<0.1$. 